\title{
AIF-1 and RNASET2 Play Complementary Roles in the Innate Immune Response of Medicinal Leech
}

\author{
Nicolò Baranzini ${ }^{a} \quad$ Laura Monti $^{a} \quad$ Marta Vanotti $^{a} \quad$ Viviana T. Orlandi ${ }^{a}$ \\ Fabrizio Bolognese $^{a}$ Debora Scaldaferri ${ }^{a}$ Rossana Girardello ${ }^{a}$ \\ Gianluca Tettamanti $^{\mathrm{a}}$ Magda de Eguileor ${ }^{\mathrm{a}}$ Jacopo Vizioli ${ }^{\mathrm{b}}$ Roberto Taramelli ${ }^{\mathrm{a}}$ \\ Francesco Acquati ${ }^{\mathrm{a}}$ Annalisa Grimaldi ${ }^{\mathrm{a}}$

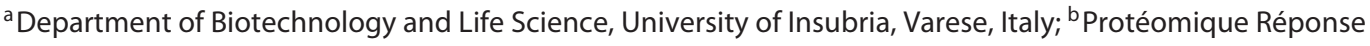 \\ Inflammatoire Spectrométrie de Masse - PRISM, University of Lille, Lille, France
}

\author{
Keywords \\ Leech innate immunity · RNASET2 - Allograft inflammatory \\ factor-1 - Macrophages · Granulocytes
}

\begin{abstract}
Recent studies demonstrated that allograft inflammatory factor-1 (AIF-1) and RNASET2 act as chemoattractants for macrophages and modulate the inflammatory processes in both vertebrates and invertebrates. The expression of these proteins significantly increases after bacterial infection; however, the mechanisms by which they regulate the innate immune response are still poorly defined. Here, we evaluate the effect of bacterial lipopolysaccharide injection on the expression pattern of these genes and the interrelation between them during innate immune response in the medicinal leech, an invertebrate model with a simple anatomy and a marked similarity with vertebrates in inflammatory processes. Collectively, prokaryotic-eukaryotic co-cultures and in vivo infection assays suggest that RNASET2 and AIF-1 play
\end{abstract}

\begin{tabular}{ll}
\hline KARGER & $\begin{array}{l}\text { ( } 2018 \text { The Author(s) Karger } \\
\text { Published by S. Karger AG, Basel Open cacess }\end{array}$ \\
E-Mail karger@karger.com & This article is licensed under the Creative Commons Attribution- \\
www.karger.com/jin & $\begin{array}{l}\text { NonCommercial-NoDerivatives 4.0 International License (CC BY- } \\
\text { NC-ND) (http://www.karger.com/Services/OpenAccessLicense). } \\
\text { Usage and distribution for commercial purposes as well as any dis- } \\
\text { tribution of modified material requires written permission. }\end{array}$
\end{tabular}

a crucial role in orchestrating a functional cross-talk between granulocytes and macrophages in leeches, resulting in the activation of an effective response against pathogen infection. RNASET2, firstly released by granulocytes, likely plays an early antibacterial role. Subsequently, AIF-1 ${ }^{+}$RNASET2recruited macrophages further recruit other macrophages to potentiate the antibacterial inflammatory response. These experimental data are in keeping with the notion of RNASET2 acting as an alarmin-like molecule whose role is to locally transmit a "danger" signal (such as a bacterial infection) to the innate immune system in order to trigger an appropriate host response.

(C) 2018 The Author(s)

Published by S. Karger AG, Basel

\section{Introduction}

The innate immune response serves not only to counteract infections (either naturally occurring or following injury) but also to maintain tissue homeostasis and func-
Prof. Annalisa Grimaldi and Prof. Francesco Acquati

Department of Biotechnology and Life Science, University of Insubria Via J.H. Dunant 3

IT-21100 Varese (Italy)

E-Mail annalisa.grimaldi@ uninsubria.it and francesco.acquati@uninsubria.it 
tional integrity, thus restoring the architectural structure to damaged organs and tissues [1]. In this context, efficient clearance of cellular debris by macrophages is known to prevent the persistence of potentially toxic or immunogenic material in the tissue environment and at the same time promotes tissue regeneration. A wide range of cytokines produced by inflammatory cells, including macrophages themselves, mainly orchestrates these processes. Thus, the generation of a rapid inflammatory response plays key roles in both host defense and tissue repair.

Several studies have demonstrated the importance of macrophages in the production and secretion of different molecules such as growth factors and cytokines, which induce vessels and mesenchymal cell recruitment to injured/grafted or bacteria-infected tissues. Among these cytokines, two macrophage-derived interesting molecules have been recently demonstrated to be involved in inflammatory responses and tissue regeneration: allograft inflammatory factor-1 (AIF-1) and the RNASET2, a member of ribonuclease T2 family [2-4].

AIF-1 is a $17-\mathrm{kDa}$ calcium-binding protein originally identified in rat cardiac transplant subject to chronic rejection and later found to be selectively expressed in macrophages and neutrophils [5]. Subsequently, several AIF1-like factors showing high amino acid sequence conservation have been identified in other metazoans (both vertebrates $[6,7]$ and invertebrates $[8-11])$. AIF-1 expression was shown to increase significantly after transplantation, wound healing, or bacterial infections, strongly suggesting its involvement in the inflammatory response and in immune system regulation by attracting macrophages to the challenged area.

Ribonucleases (RNases) are hydrolytic enzymes that cut phosphodiester bonds within RNA molecules and represent one of the most versatile enzyme families, involved in an impressively wide range of biological processes [12]. Among the different ribonuclease families, the transferase-type RNase subfamily is split into three main groups: A, T1, and T2 RNases, among which only T2 RNases have been reported in all phyla examined so far, suggesting a very ancient and evolutionary crucial role for this subclass of ribonucleases [12]. Moreover, a growing interest has been recently focused on T2 RNase family members, due their key role in several critical biological processes such as angiogenesis, biogenesis of ribosomes, apoptosis, cell proliferation control and, most interestingly, regulation of immune response [13]. For instance, the human RNASET2 protein, which acts as a tumor suppressor in different types of cancer, has been reported to trigger the innate immune response by re-

AIF-1 and RNASET2 in Leech Innate Immune Response cruiting host macrophages endowed with oncosuppressive properties toward the tumor mass in vivo $[13,14]$. Moreover, other members of the T2 RNase family have recently been shown to carry out a modulatory role in the immune response as well $[15,16]$.

Although it is now acknowledged that both AIF-1 and RNASET2 play a crucial role in activating and modulating the innate immune response, the mechanism(s) by which they act are largely unexplored. A better understanding of the interplay between these two molecules may thus provide valuable insights into how the innate immune system regulates inflammation, disease development, or wound healing and at the same time yield valuable new therapeutics and interventional strategies to control immune and systemic responses to disease, injury, and bacterial infection.

Here, we propose the medicinal leech Hirudo verbana as a well-established experimental model to investigate the above-mentioned processes related to the innate immune response. Indeed, this invertebrate represents a cost-effective and easily manipulable model and without significant ethical considerations in relation to its use. In addition, its simple anatomy, physiological characteristics, and the less varied repertoire of cell types involved in immune response and wound healing allow to easily define the cellular and molecular mechanisms linked to these biological processes $[17,18]$.

Differently from other Annelids (i.e., oligochaetes and polychaetes), leeches have a parenchymatous body and a reduced coelom $[19,20]$. As previously mentioned, the anatomy of leech is relatively simple (Fig. 1): underneath the epithelium, muscle fibers are organized in fields, surrounded by a scant extracellular matrix. The muscular sac is separated from the inner digestive tube by a loose connective tissue containing the botryoidal and the vasofibrous tissues [19-21], from which most of the myeloid lineages-derived leucocytes arise [18].

In healthy medicinal leech, a few resident immunocompetent cells, such as macrophages, type I and II granulocytes, and natural killer cells are poorly represented in the extracellular matrix surrounding muscle [22]. These immunocytes display features and behaviors typical of those found in vertebrates [23-25]. Moreover, a plethora of cytokines, growth factors, and cluster of differentiation proteins (CDs) have been reported in leeches, where they act as modulators of these processes in a very similar way when compared to vertebrates [25-28]. In fact, our previous investigations showed that injection in leeches of human cytokines and growth factors promotes hematopoiesis, vascular growth, immune cell migration, and myofi-

J Innate Immun 2019;11:150-167 151 
Fig. 1. Drawing representing a general view of leech body in cross section. Under the cuticle and epithelium, the muscle fibers and gut are visible, and between them a loose connective tissue containing the botryoidal and the vasofibrous tissue can be seen. Modified from Grimaldi et al. [55].

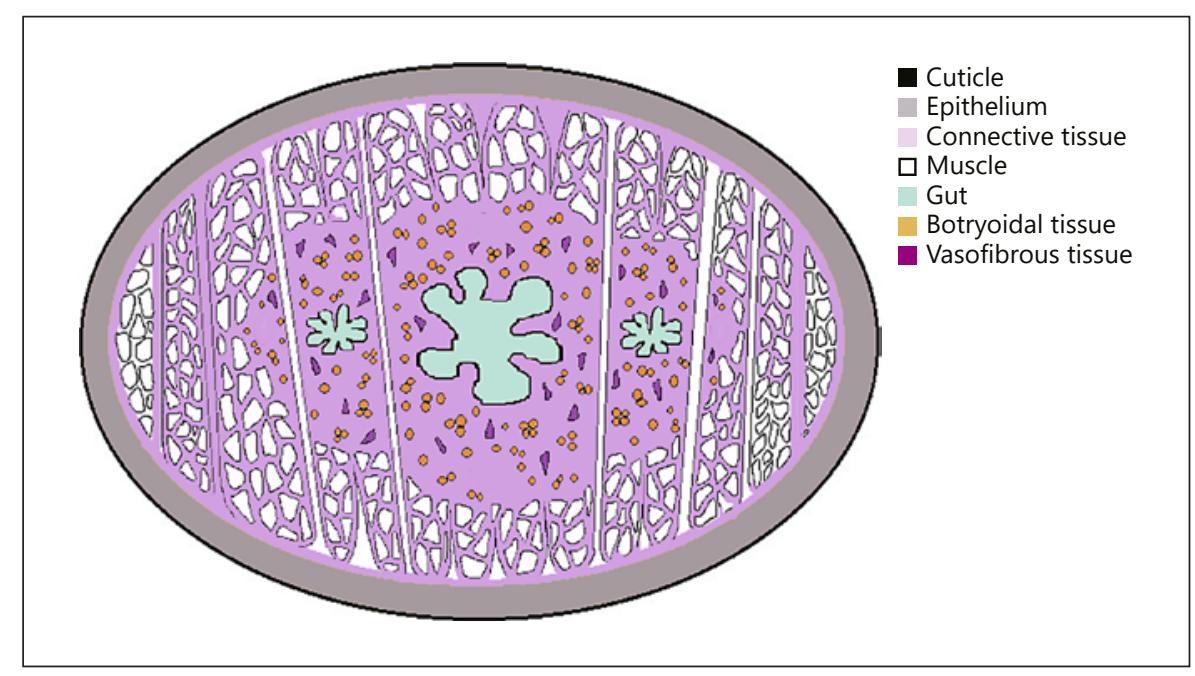

broblast differentiation [17]. Among these factors, AIF-1 and RNASET2 have recently been shown to play a pivotal role in the leech immune response and tissue repair $[2,3,11]$. Indeed, expression of both factors is significantly increased following lipopolysaccharides (LPS) or bacterial infection in leeches. We have previously demonstrated that the injection in the leech body wall of LPS induces a massive migration of macrophages towards the stimulated area. These immune cells in turn express and produce AIF-1 and RNASET2, both involved in other macrophage recruitment $[2,4]$.

Based on these previous studies, we demonstrate for the first time an interrelation between these two molecules, which orchestrate a functional cross talk between granulocytes and macrophages. In particular, we show that RNASET2 is firstly released by granulocytes to play an early antibacterial role. Subsequently, RNASET2 recruits AIF- $1^{+}$macrophages with phagocytic activities in order to potentiate the antibacterial inflammatory response.

\section{Materials and Methods}

\section{Animals and Treatment}

Leeches ( $H$. verbana, Annelida, Hirudinea, from Ricarimpex, Eysines, France) were kept in lightly salted water $(\mathrm{NaCl} 1.5 \mathrm{~g} / \mathrm{L})$ at $19-20{ }^{\circ} \mathrm{C}$ in aerated tanks. Animals were randomly divided into separate experimental groups ( 5 individuals for each time point). Each injection was performed in the body wall at the level of the 20th metamere on leeches anesthetized by immersing them in a $10 \%$ ethanol solution. Treated and untreated (control) animals were anesthetized and then dissected to remove body wall tissues at specific time points. Samples were processed for optical and electron microscopy and immunofluorescence protocols. Animals were randomly split into three groups ( 5 individuals from each time point) and submitted to various protocols and treatments.

Group 1. Unstimulated control or iso-osmotic PBS solution (138 mM NaCl, $2.7 \mathrm{mM} \mathrm{KCl}, 4.3 \mathrm{mM} \mathrm{Na}_{2} \mathrm{HPO}_{4}, 1.5 \mathrm{mM} \mathrm{KH}_{2} \mathrm{PO}_{4}$, $\mathrm{pH}$ 7.4)-injected leeches, to verify the normal and correct morphological information about the body organization and to demonstrate that both the saline solution and the injection did not induce any immune response.

Group 2. T 30 min, T 1 h, T 3 h, T 6 h, T 24 h: samples injected with $100 \mu \mathrm{L}$ sterilized PBS containing, respectively, $100 \mathrm{ng} / \mathrm{mL}$ LPS from Escherichia coli (Serotype 0111: B4, Sigma, St. Louis, MO, USA).

Group 3. T 30 min: samples injected with a solution of PBS containing Pseudomonas aeruginosa PAO1 (expressing the green fluorescent protein $[\mathrm{GFP}]$ ) alone or added with an anti-RNASET2 antibody for functional blocking experiments.

\section{Optical and Electron Microscopy}

Tissues were fixed for $2 \mathrm{~h}$ in $0.1 \mathrm{M}$ cacodylate buffer at $\mathrm{pH}$ 7.4, containing $2 \%$ glutaraldehyde, washed in the same buffer and postfixed for $1 \mathrm{~h}$ with $1 \%$ osmium tetroxide in cacodylate buffer, $\mathrm{pH}$ 7.4. After standard ethanol dehydration, specimens were embedded in an Epon-Araldite 812 mixture (Sigma-Aldrich, Milan, Italy). Sections were obtained with a Reichert Ultracut $S$ ultratome (Leica, Wien, Austria). Semi-thin sections ( $0.75 \mu \mathrm{m}$ in thickness) were stained by crystal violet and basic fuchsin [29] and observed under the light microscope Nikon Eclipse Ni (Nikon, Tokyo, Japan). Data were recorded with a DS-5 M-L1 digital camera system (Nikon). Ultrathin sections $(80 \mathrm{~nm}$ ) were placed on copper grids, stained by uranyl acetate and lead citrate and observed with a Jeol 1010 EX electron microscope (Jeol, Tokyo, Japan). Data were recorded with a MORADA digital camera system (Olympus, Tokyo, Japan).

\section{Western Blot Assays}

Tissues from injected and uninjected animals were immediately frozen in liquid nitrogen and then homogenized with a mortar. The homogenates were suspended in RIPA buffer $(150 \mathrm{mM}$ 
$\mathrm{NaCl}, 1 \% \mathrm{NP}-40,0.5 \%$ sodium deoxycholate, $0.1 \%$ SDS, $50 \mathrm{mM}$ Tris- $\mathrm{HCl}, \mathrm{pH} 8.0$ ), at a concentration of $10 \mu \mathrm{L}$ per mg of tissue, in the presence of a protease inhibitor cocktail (Sigma-Aldrich). The particulate material was removed by centrifugation at $15,100 \mathrm{~g}$ for $10 \mathrm{~min}$ at $4{ }^{\circ} \mathrm{C}$ in a refrigerated Eppendorf Minispin microcentrifuge (Hamburg, Germany). $30 \mu \mathrm{L}$ of supernatants $(40 \mu \mathrm{g} / \mathrm{mL})$ containing total protein extract of 1 leech (in total 3 different animals were used for each treatment), were denatured at $100^{\circ} \mathrm{C}$ for $10 \mathrm{~min}$ and were loaded on $12 \%$ acrylamide minigels for SDS-PAGE analyses. Molecular weights were determined by concurrently running broad-range standards from Bio-Rad (Richmond, MA, USA). Proteins separated by SDS-PAGE were transferred onto Bio-Rad nitrocellulose filters. Membranes were then saturated with 5\% nonfat dried milk in Tris-buffered saline (TBS; $20 \mathrm{mM}$ TRIS- $\mathrm{HCl}$ buffer, $500 \mathrm{mM} \mathrm{NaCl}, \mathrm{pH} \mathrm{7.5)}$ at room temperature for $2 \mathrm{~h}$ and incubated for $90 \mathrm{~min}$ with a rabbit polyclonal anti-RNASET2 [30] or an anti-HmAIF-1 [11] antibody (1:5,000 dilution in 5\% TBSmilk). After three washes with TBS-Tween $0.1 \%$, antigens were revealed with a secondary anti-rabbit IgG antibody conjugated to horseradish peroxidase (Jackson ImmunoResearch Laboratories), diluted at 1:5,000. Immunocomplexes were revealed with luminol LiteAblot PLUS Enhanced Chemiluminescent Substrate (EuroClone, Pero, Italy). In control experiments, anti-RNASET2 [13, 14] and anti-HmAIF-1 (specific for medicinal leech macrophage $[4,11])$ antibodies were substituted with rabbit preimmune serum $(1: 20,000)$. Bands were normalized by using the ImageJ software package (http://rsbweb.nih.gov/ij/download.html), and the housekeeping protein D-glyceraldehyde-3-phosphate dehydrogenase $(\mathrm{GAPDH})$, used as an internal reference, was detected with a rabbit polyclonal anti-human GAPDH IgG (Proteintech, Chicago, IL, USA), diluted at 1:2,000.

\section{Immunohistochemistry}

Tissue samples were embedded in Polyfreeze tissue-freezing medium (OCT, Tebu-Bio, Le Perray-en-Yvelines, France/Polysciences, Eppelheim, Germany), immediately frozen in liquid nitrogen, and then kept at $-80^{\circ} \mathrm{C}$. Cryosections $(7 \mu \mathrm{m})$ obtained with a cryotome (Leica CM1850) were collected on gelatinous slides and kept at $-20^{\circ} \mathrm{C}$.

For double-labelling immunofluorescence assays, sections were rehydrated with PBS $1 \times$ for 10 min and then preincubated for 30 min with blocking solution (2\% bovine serum albumin and $0.1 \%$ Tween 20 in PBS) that block the nonspecific sites. The same blocking solution was used to dilute the following primary antibodies: rabbit anti-RNASET2 (1:100); goat anti-CD11b (Santa Cruz Biotechnology, CA, USA), known to react with leech granulocytes [25] (1:100); rabbit anti-HmAIF-1, (1:1,000). After several washes, specimens were incubated for $45 \mathrm{~min}$ with the following secondary antibodies (Abcam, Cambridge, UK): goat anti-rabbit Cy5 conjugated (excitation filter $650 \mathrm{~nm}$, emission filter $672 \mathrm{~nm}$ ), donkey anti-goat Cy5 conjugated, or donkey anti-rabbit fluorescein isocyanate (FITC)/conjugated (excitation filter $493 \mathrm{~nm}$, emission filter $518 \mathrm{~nm}$ ), all diluted at 1:200. Sections were treated with $1 \mathrm{mM} \mathrm{CuSO}_{4}$ in $50 \mathrm{nM}$ ammonium acetate buffer ( $\mathrm{pH}$ 5.0) for 15 min and then washed in distilled water and PBS for reducing tissue autofluorescence while preserving the specific fluorochrome signal [31]. In all control experiments, primary antibodies were substituted with rabbit preimmune serum (1:100) or were omitted, and sections were incubated only with the secondary antibodies. Nuclei were stained by incubating for 3 min with 4',6-diamidino- 2-phenylindole (DAPI; $0.1 \mathrm{mg} / \mathrm{mL}$ in PBS, excitation $340 \mathrm{~nm}$, emission $488 \mathrm{~nm}$ ). The slides were examined with a Nikon fluorescence microscope. Images were combined with Adobe Photoshop (Adobe Systems, San Jose, CA, USA).

\section{Immunogold}

Samples were fixed for $2 \mathrm{~h}$ at $4{ }^{\circ} \mathrm{C}$ with $4 \%$ paraformaldehyde and $0.5 \%$ glutaraldehyde in PBS, dehydrated in ethanol series and embedded in an Epon-Araldite 812 mixture (Sigma-Aldrich). Ultrathin sections, obtained as above, were collected on gold grids (300 mesh). After etching with $\mathrm{NaOH} 3 \%$ in absolute ethanol [32], they were incubated for $30 \mathrm{~min}$ in blocking solution containing PBS, $1 \%$ bovine serum albumin, and $0.1 \%$ Tween and then with the polyclonal primary antibody rabbit anti-human RNASET2 diluted at 1:20 in blocking solution. After several washings with PBS, the primary antibody was visualized by immunostaining with the secondary goat anti-rabbit IgG $(\mathrm{H}+\mathrm{L})$-gold conjugate antibody (GE Healthcare, Amersham, UK; particle size, $10 \mathrm{~nm}$ ) diluted at 1: 100 in blocking solution for $1 \mathrm{~h}$. In control experiments, the primary antibody was omitted or was substituted with the rabbit preimmune serum (1:100), and sections were incubated with secondary antibody alone. After several washings with PBS, samples were treated for 5 min with PBS containing $0.5 \%$ glutaraldehyde, counterstained with uranyl acetate and observed under a Jeol 1010 EX transmission electron microscope (Jeol).

\section{Cell Culture Lines and Bacterial Strain Growth Conditions}

The human promonocytic THP-1 cell line [33] was cultured in RPMI-1640 media, 10\% FBS, 1\% glutamine. The silence RNASET2 THP-1 SH cell line was cultured in the same medium supplemented with $0.75 \mu \mathrm{g} / \mathrm{mL}$ puromycin. Both cell lines were maintained in a humidified incubator $\left(37^{\circ} \mathrm{C}, 5 \% \mathrm{CO}_{2}\right)$. THP-1 cells were differentiated into macrophages by addition of $5 \mathrm{ng} / \mathrm{mL}$ phorbol 12 -myristate 13-acetate for $48 \mathrm{~h}$ in MT12 wells at a concentration of 0.65 $\times 10^{6}$ cells $/ \mathrm{mL}$.

P. aeruginosa $\mathrm{PAO} 1$ [34] was transformed using the $\mathrm{pVO}(\mathrm{GFP})$ expression vector; a pJB3 $\mathrm{KmD}$ derivative, in which the GFP coding sequence was cloned under an arabinose inducible promoter (pAra). Both strains were grown overnight in LB medium (SigmaAldrich) at $37^{\circ} \mathrm{C}$ under $200 \mathrm{rpm}$ shaking.

\section{THP-1 and $\mathrm{P}$. aeruginosa $\mathrm{PAO} 1 \mathrm{Co}-\mathrm{Cultures}$}

The medium of THP- 1 cell cultures treated for $48 \mathrm{~h}$ with phorbol was changed and three washes were performed before the bacterial inoculum. $P$. aeruginosa PAO1 expressing GFP was induced for $30 \mathrm{~min}$ with arabinose $1 \mathrm{mM}$ inoculum to THP-1 cell cultures. A sample of PAO1 cells suspended in $50 \mathrm{~mm}$ phosphate buffer, $\mathrm{pH}$ 7.4 has been dispensed to THP-1 cells (500,000 cells/well) to reach a concentration equal to $\sim 10^{7} \mathrm{CFU} / \mathrm{mL}$. Upon $2 \mathrm{~h}$ co-culture at $37^{\circ} \mathrm{C}$, GFP expression was checked through fluorescence microscopy (488/525 nm, for FITC signals). Bacterial viability was checked through a plate count technique. A volume $(0.1$ or 0.01 $\mathrm{mL}$ ) of undiluted or serially diluted samples was plated on LB agar plates and incubated for $24 \mathrm{~h}$ at $37^{\circ} \mathrm{C}$. Viable counts were ex-

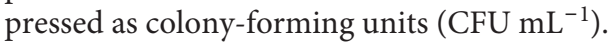

\section{Leech Infection}

Leeches were injected in the body wall, at the level of the 20th metamere, with $100 \mu \mathrm{L}$ of PBS containing P. aeruginosa PAO1 expressing GFP at a concentration equal to $10^{7} \mathrm{CFU} / \mathrm{mL}$. For func- 
tional blocking experiments, animals were injected with a sample of bacterial culture treated with $1 \mu \mathrm{L}$ of antibody anti-RNASET2 to inhibit the possible bactericidal activity of this enzyme. After 30 min, tissue samples were collected, embedded in Polyfreeze tissuefreezing medium (OCT) and immediately frozen in liquid nitrogen. Cryosections $(7 \mu \mathrm{m})$ were counterstained with crystal violet and basic fuchsin for morphological analysis and with DAPI (0.1 $\mathrm{mg} / \mathrm{mL}$ in PBS) to highlight bacterial chromosomal DNA. Specimens were then observed under a light optical microscope and fluorescence Nikon Eclipse Ni (Nikon, Japan). DAPI was visualized with excitation and emission filter $360 / 420 \mathrm{~nm}$, and to evaluate bacterial GFP, excitation and emission filter $488 / 525 \mathrm{~nm}$ was used.

\section{Statistical Analysis}

The percentages of $\mathrm{CD}_{11} \mathrm{~b}^{+} / \mathrm{RNASET}^{+}$cells were assessed by analyzing 5 different slides (random fields of $45,000 \mu \mathrm{m}^{2}$ for each slide) for each experimental time point using the Image J software package. Cells in the chosen fields were counted by hand as macrophages if they were RNASET2 ${ }^{+}$FITC labelled [2] or as granulocytes if they were $\mathrm{CD} 11 \mathrm{~b}^{+} / \mathrm{RNASET}^{+}$(yellow labelled as a result of CY5/FITC double staining). Statistical analyses were performed using Statistica 7.0 software (StatSoft Inc., Tulsa, OK, USA), and differences were calculated by one-way ANOVA followed by Fisher's post hoc test, and $p<0.05$ was considered statistically significant.

\section{Results}

We have previously reported that AIF-1 and RNASET2 are significantly upregulated at 6 and $24 \mathrm{~h}$ following LPS injection, and that this change in their expression is involved in leech macrophage recruitment $[2,3]$. However, the underlying mechanisms by which these two factors operate are still poorly characterized. For instance, it is still not clear whether they display a different temporal expression profile during the earliest phases of the inflammatory response ( $30 \mathrm{~min}$ to $24 \mathrm{~h}$ ) and what their specific role in the innate immune cell activation is. To address these issues, here we first carried out a morphological analysis on leech tissue sections from unlesioned and PBSand LPS-injected leeches to better characterize the phenotype of the immune cells activated at different time points following LPS injection. Further, the temporal expression profile of AIF-1 and RNASET2 was evaluated by Western blot and immunohistochemistry.

\section{Morphological Analysis of Leech Tissues Injected with LPS}

The immune cell population recruited following LPS injection was characterized by both optical and ultrastructural analysis. Morphological examination of the body wall showed that, in both unlesioned (Fig. 2a) and control PBS-injected leeches (Fig. 2b), macrophages (Fig. 2c) and vasofibrous tissue (Fig. 2d) were poorly represented underneath the epithelium and among muscle fibers. Of note, the vasofibrous tissue was formed by vasocentral cells showing an electron-dense cytoplasm containing a few large granules and by vasofibrous cells characterized by a cytoplasm filled with several small highly electron-dense granules (Fig. 2d). As previously reported, following LPS stimulation the vasocentral and vasofibrous cells dissociated from each other $[35,36]$, and the vasofibrous cells gave rise to type I granulocytes [37]. Indeed, 30 min after LPS injection, several vasofibrous tissue cells crossing the thick muscle layers were readily recognizable by light microscopy due to their dark pigmentation (Fig. 2e). By transmission electron microscopy (TEM) analysis, vasofibrous cell-derived type I granulocytes [37] were clearly recognizable underneath the epithelium and characterized by small round electron-dense granules (Fig. 2f). At $6 \mathrm{~h}$ following LPS injection (Fig. 3ac), numerous type I granulocytes and macrophages were readily detected in the injected area in both connective tissue surrounding the muscle fibers and underneath the epithelial region. Macrophages were clearly recognizable by their irregular membrane border, involved in the formation of pseudopodia (Fig. 3a-b1), a typical feature of cells engaged in active migration and phagocytosis. Significantly, ultrastructural TEM analysis also showed that recruited macrophages in LPS-challenged areas were strictly associated with type I granulocytes (Fig. 3b1). Indeed, at $6 \mathrm{~h}$ following LPS stimulation, numerous macrophages were detected also underneath the epithelium close to type I granulocytes, characterized by a large nucleus and small electron-dense granule-filled cytoplasm (Fig. 3d, c). Interestingly, some granulocytes apparently emptied of their granules were also present (Fig. 3e), suggesting that these cells were releasing antimicrobial and/ or cytotoxic molecules from their granules in the extracellular environment, as already described for other invertebrates $[38,39]$.

\section{Western Blot Analysis of AIF-1 and RNASET2 in \\ LPS-Injected Medicinal Leech}

In order to better characterize the temporal expression profiles of AIF-1 and RNASET2, Western blot assays were performed in LPS- and control PBS-injected leeches at different time points after treatment (30 $\mathrm{min}, 1,3,6$, and $24 \mathrm{~h}$ ) (Fig. $4 \mathrm{a}-\mathrm{f}$ ). Immunoblot analysis on protein extracts of tissue sections from control, PBS-injected areas confirmed the presence in leech tissues of an AIF1-immunoreactive band at about $18 \mathrm{kDa}$, corresponding 


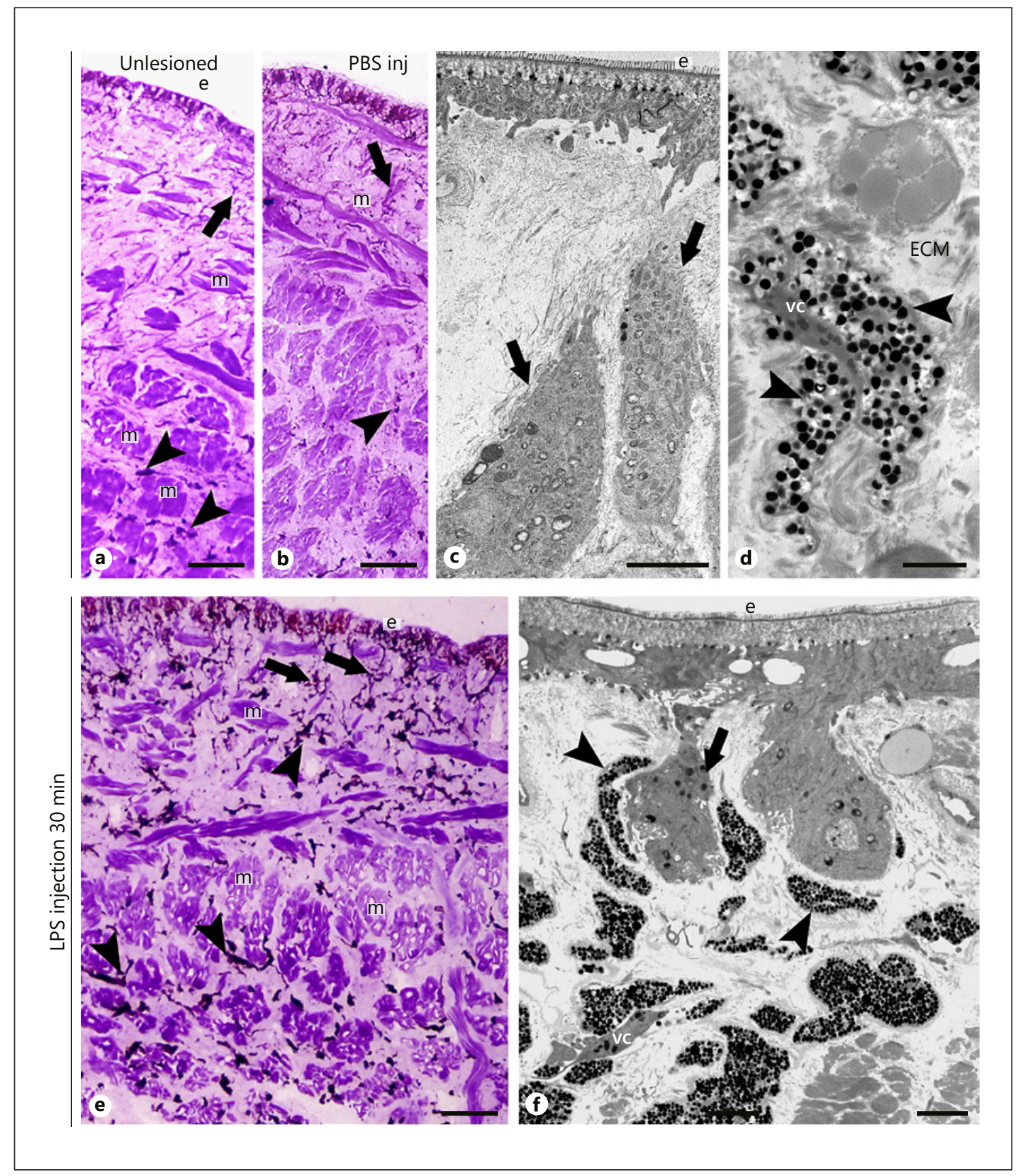

Fig. 2. Morphological analysis of leech body wall at optical and TEM microscopes 30 min after PBS and LPS injection. Few resident macrophages (arrow) and vasofibrous tissue cells (arrowheads) are visible underneath the epithelium (e) or among the muscle fibres $(\mathrm{m})$ in unlesioned (a) and in PBS-injected animals (b). Detailed TEM of macrophages (arrows in c) and of the vasofibrous tissue (d) surrounded by extracellular matrix (ECM) formed by vasocentral cell (vc), with cytoplasm containing a few granules, surrounded by vasofibrous cells (arrowheads), with a cytoplasm containing numerous small highly electron-dense granules. 30 min after LPS injection $(\mathbf{e}, \mathbf{f})$, numerous vasofibrous tissue cells are recognizable by their dark color (arrowheads in $\mathbf{e}$ ) among muscle fibers and underneath the epithelium (e). f Detailed view of type I granulocytes (arrowheads) detached from vasocentral cells (vc) and next to resident macrophages (arrow) localized in the subepithelial region (e). Bars in $\mathbf{a}, \mathbf{b}, \mathbf{e}: 100 \mu \mathrm{m}$; bar in c, d: $2 \mu \mathrm{m}$; bar in f: $10 \mathrm{~nm}$. 


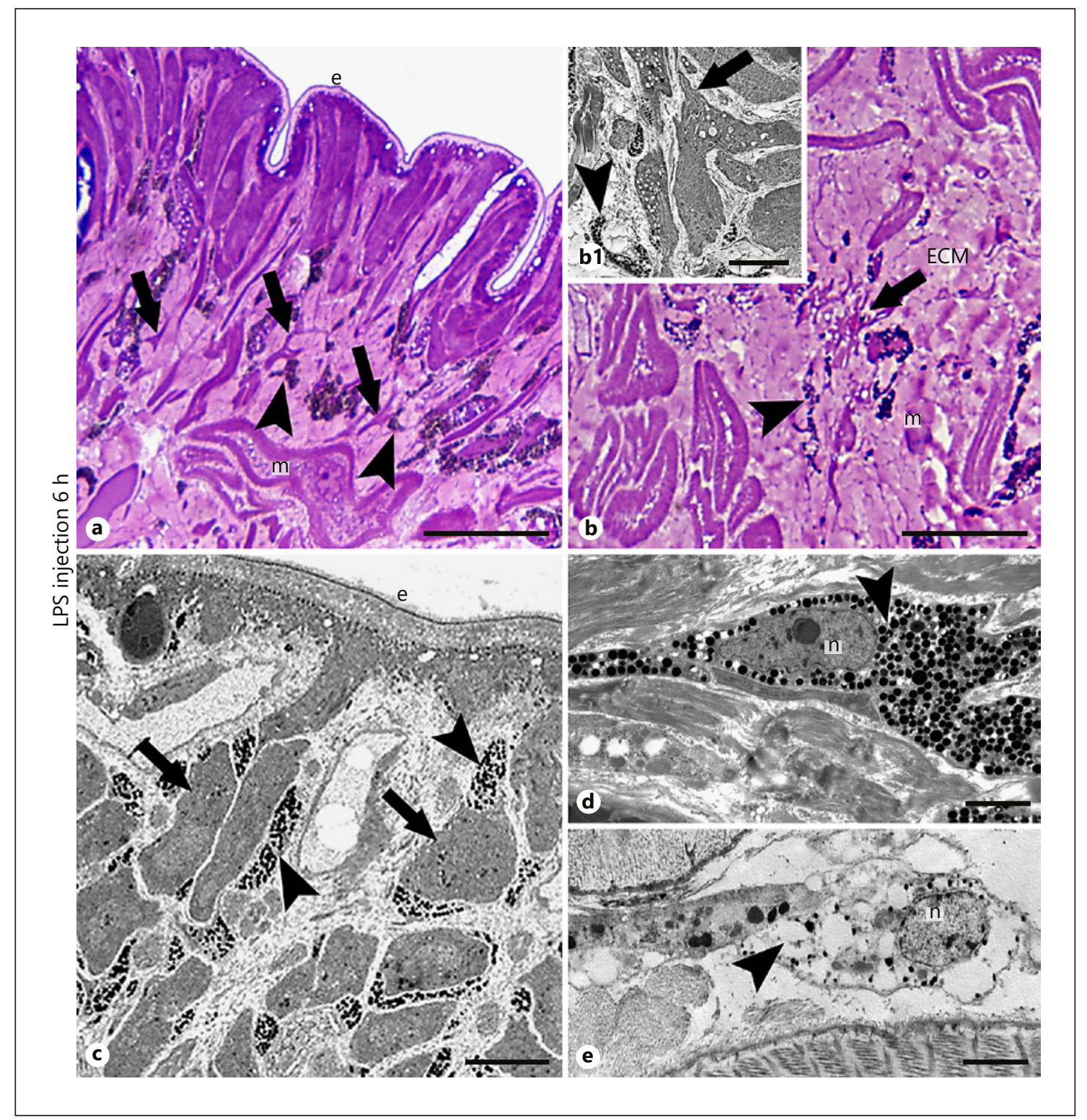

Fig. 3. Morphological analysis of leech body wall at optical and TEM microscopes $6 \mathrm{~h}$ after LPS injection. a, b Optical images show numerous macrophages (arrows) and type I granulocytes (arrowheads) underneath the epithelium (e) and localized in the extracellular matrix surrounding the muscle fibers $(\mathrm{m})$. Ultrastructure

to the expected molecular weight for this protein [4], and of two main RNASET2-immunoreactive bands of approximately $36 \mathrm{kDa}$ (the known secreted form) and 29 $\mathrm{kDa}$ (a known intracellular form especially visible only in a subset of the tested samples), respectively $[2,40]$.

Strikingly, in the protein extracts from LPS-injected tissue areas, not only did the amount of both proteins increase significantly, their expression profile turned out to
TEM images show that macrophages (arrows in c) are characterized by pseudopodia (arrow in b1) and are in close contact with type I granulocytes (arrowheads in b1, $\mathbf{c}$, and $\mathbf{d}$ ), some of which are undergoing the degranulation process (e). $n$, nuclei. Bars in $\mathbf{a}$, b: $20 \mu \mathrm{m}$; bar in b1: $2 \mu \mathrm{m}$; bar in c: $4 \mu \mathrm{m}$; bar in d, e: $2 \mu \mathrm{m}$.

be quite different as well (Fig. 4c, d). In particular, AIF-1 expression was highly increased from the earliest phases of LPS-mediated inflammation (30 $\mathrm{min})$, and then it slightly decreased up to $24 \mathrm{~h}$ after treatment. Interestingly, the trend for RNASET2 expression following LPS injection was quite different, since this protein showed two distinct peaks of expression, at $30 \mathrm{~min}$ and $6 \mathrm{~h}$ from stimulation. 


\section{AIF-1 and RNASET2 Tissue Localization}

The expression profile of AIF-1 and RNASET2 was also analyzed by double immunofluorescence staining, using both anti-HmAIF-1 and anti-RNASET2 polyclonal antibodies on cryosections obtained from unlesioned and PBS-injected leeches (Fig. 5a-c1) compared to LPS-challenged leeches (Fig. 5d-i1).

As previously demonstrated $[2,3]$, double immunofluorescence assays confirmed that the two proteins are constitutively expressed in unlesioned (Fig. 5a) and in PBS-injected animals (Fig. 5b). However, the signal intensity detected for both proteins significantly changed following injection with LPS. In general, the number of cells positive for both AIF-1 and RNASET2 significantly increased following LPS injection, although AIF-1 ${ }^{-/}$ RNASET $2^{+}$cells were also detected at specific time points. In particular, several AIF- $1^{+} / \mathrm{RNASET}^{+}$cells were detected at $30 \mathrm{~min}$ and $1,3,6$, and $24 \mathrm{~h}$ after treatment

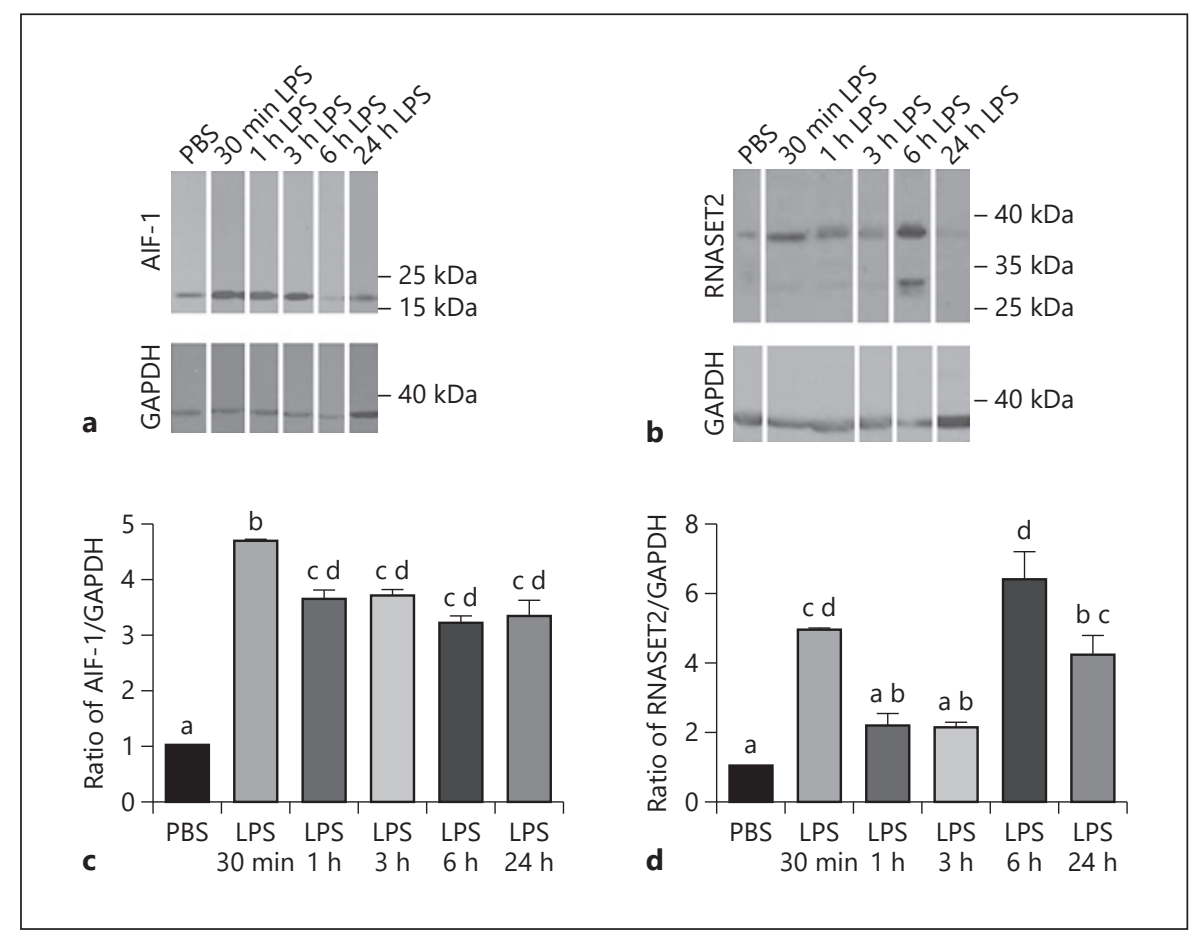

Fig. 4. AIF-1 and RNASET2 Western blot analysis. Proteins extracted from 3 PBS- and LPS-injected leeches and probed with anti-HmAIF-1 (a) and anti-RNASET2 (b) antibodies. The housekeeping protein D-glyceraldehyde-3-phosphate dehydrogenase (GAPDH) was used as a loading control, and band intensity appeared to be similar in each loaded sample. The anti-HmAIF-1 antibody detected a specific immunoreactive band of about 18 $\mathrm{kDa}$, while two bands of approximately $36 \mathrm{kDa}$ (the extracellular form) and $29 \mathrm{kDa}$ (the intracellular form) were detected by the anti-RNASET2 antibody. c, $\mathbf{d}$ The levels of expression were quantified by densitometry using the Image J software package, and the obtained graphs show the level of expression of the two factors. $\mathbf{d}$ The graphic is based on the RNASET2 extracellular form. The in- dividual signals from each lane have been cropped from larger digital images, which are available as supplementary information (see www.karger.com/doi/ 10.1159/000493804 for all supplementary material). Statistical differences were calculated by one-way ANOVA followed by Tukey's post hoc test, and $p<0.05$ was considered statistically significant (between PBS and LPS treatments). Means with different letters indicate significant difference between PBS and LPS treatments at different times. Experiments were performed in triplicate, and data represent mean values \pm SEM. Statistical analyses were performed using Statistica 7.0 software (StatSoft Inc., Tulsa, OK, USA), and differences were calculated by oneway ANOVA followed by Fisher's post hoc test, and $p<0.05$ was considered statistically significant.
Fig. 5. Immunofluorescence analyses. Immunofluorescence assays (a-h) of leech body wall sections. In unlesioned (a) and PBS-injected animals (b), a few cells located close to the epithelium (e) and among muscle fibers ( $\mathrm{m}$ ) are visible and express HmAIF-1 (in red) and RNASET2 (in green), whereas after LPS injection several migrating immune-responsive cells are visible in the epithelial region and among muscles $(\mathrm{m})(\mathbf{d}-\mathbf{h})$. No signal is detected in negative control experiments in which the primary antibodies were omitted $(\mathbf{c}, \mathbf{i})$ or substituted by preimmune serum $(\mathbf{c} \mathbf{1}, \mathbf{i 1})$. Cell nuclei stained blue by treatment with DAPI. Bars: $100 \mu \mathrm{m}$.

(For figure see next page.) 


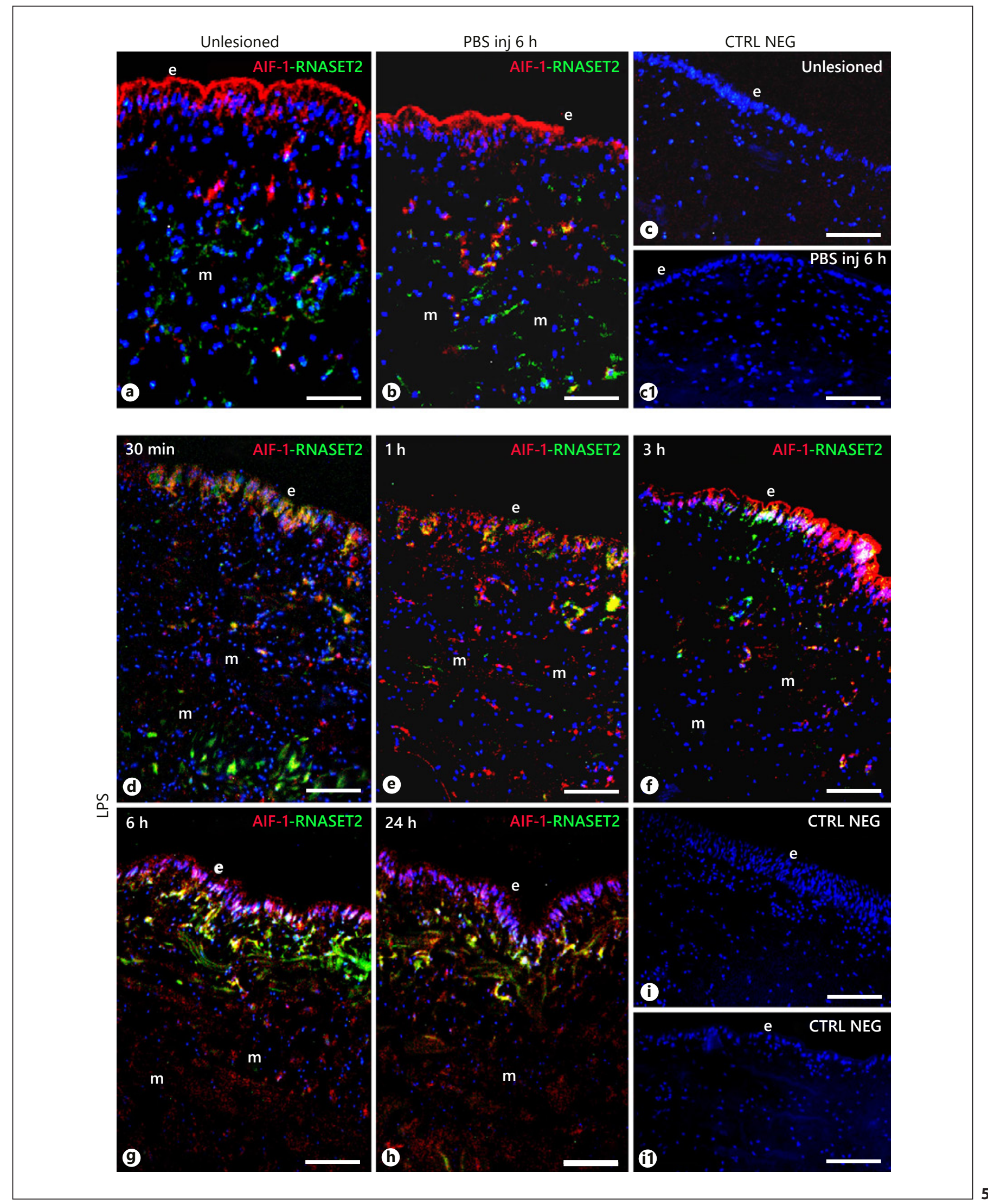




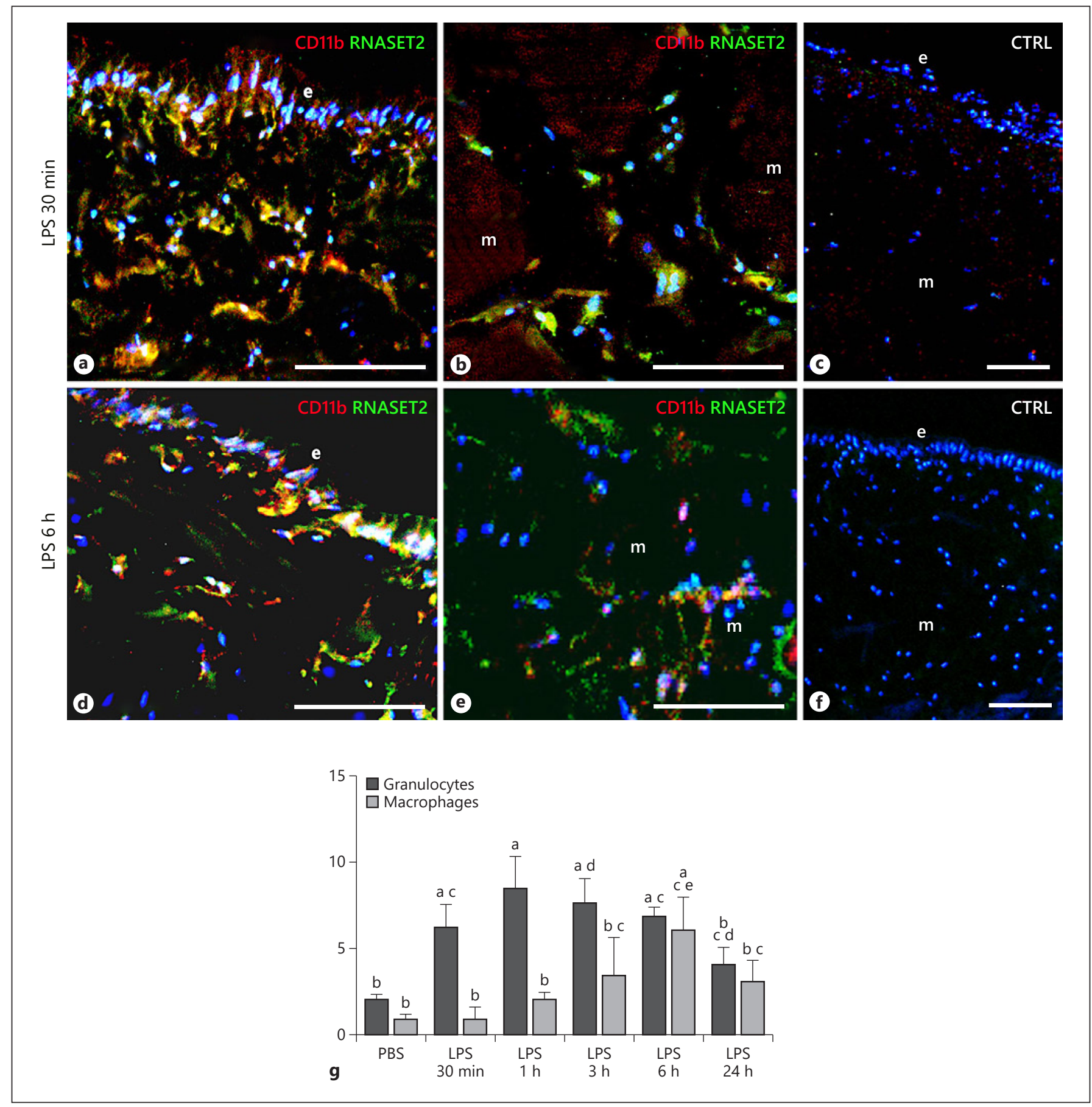

Fig. 6. Double immunolocalization of RNASET2 and CD11b or RNASET2 and HmAIF- 1 in animals $30 \mathrm{~min}$ and $6 \mathrm{~h}$ following LPS injection. Numerous RNASET2 ${ }^{+} / \mathrm{CD} 11 \mathrm{~b}^{+}$type I granulocytes (yellow in $\mathbf{a}, \mathbf{b}$ ) and RNASET $2^{+} / \mathrm{HmAIF}-1^{+}$macrophages (yellow in $\mathbf{d}$, e) migrating towards the injected area are visible under the epithelium (e) and among the muscle fibers (m). Double immunostaining was performed with anti-RNASET2 (green) anti-CD11b or anti HmAIF-1 (red). c, f No signal was detected in negative control experiments in which the primary antibodies were omitted. Cell nuclei stained blue by treatment with DAPI. Bars: $50 \mu \mathrm{m}$. g The percentages of granulocytes (RNASET $2^{+} / \mathrm{CD} 11 \mathrm{~b}^{+}$) and of macrophages (RNASET $2^{+} / \mathrm{CD} 11 \mathrm{~b}^{-}$) were assessed by analyzing 5 different slides ( 10 random fields of $45,000 \mu \mathrm{m}^{2}$ for each slide) using the Image J software package. Statistical differences were calculated by factorial ANOVA followed by Tukey's post hoc test, and $p<0.05$ was considered statistically significant (between PBS- and LPSchallenged leeches). Means with different letters indicate significant difference between the number of granulocytes and macrophages in untreated animals. 
(Fig. 5d-h), whereas AIF-1 ${ }^{-} /$RNASET2 $^{+}$cells were mainly observed at $30 \mathrm{~min}$ and $6 \mathrm{~h}$ after treatment (Fig. 5d, g), in keeping with the observed pattern of RNASET2 expression shown by Western blot analysis. No signal was detected in negative control experiments in which primary antibodies were substituted with blocking solution (Fig. 5c, i) or preimmune serum (Fig. 5c1, i1).

These data suggested that, besides macrophages, other types of immune cells were expressing RNASET2, and based on morphological analysis, we hypothesized that these AIF-1 ${ }^{-} / \mathrm{RNASET}^{+}$cells might represent type I granulocytes.

\section{Immunophenotype Characterization of LPS-Induced} Migrating Immune Cell Populations

To further characterize the $\mathrm{AIF}^{+} / \mathrm{RNASET}^{+}$and $\mathrm{AIF}^{-} / \mathrm{RNASET}^{+}{ }^{+}$cell populations recruited to LPS-challenged areas, we performed double-staining experiments using an anti-CD11b antibody to detect leech granulocytes [25], and an anti-RNASET2 antibody. The experiments showed that, 30 min (Fig. $6 \mathrm{a}-\mathrm{c}$ ) and $6 \mathrm{~h}$ (Fig. $6 \mathrm{~d}$, e) following LPS stimulation, both $\mathrm{CD}_{11} \mathrm{~b}^{+} / \mathrm{RNASET}^{+}$ and $\mathrm{CD} 11 \mathrm{~b}^{-} / \mathrm{RNASET}^{+}$cells gathered at the injection area and were mainly localized underneath the epithelium (Fig. 6a, d) and among the muscle fibers (Fig. 6d, e). Interestingly, cell counting performed on five representative images of $\mathrm{CD} 11 \mathrm{~b}^{+}$cells at each time lapse showed

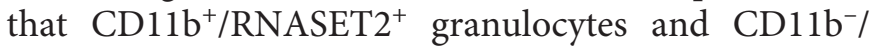
RNASET ${ }^{+}$macrophage cell numbers were differently distributed during the different phases of the inflammatory response. Indeed, the number of granulocytes largely increased just $30 \mathrm{~min}$ following stimulation, remained high at $6 \mathrm{~h}$ and then decreased and returned to a baseline level at $24 \mathrm{~h}$ from stimulation. By contrast, the number of infiltrating macrophages was lower than that of granulocytes in the early inflammatory phase, but it grew gradually in later phases to reach a peak at $6 \mathrm{~h}$ from stimulation.

The presence of RNASET2 in $\mathrm{CD}_{11 \mathrm{~b}}{ }^{+}$RNASET2 ${ }^{+}$ leech granulocytes was also confirmed by immunogold staining in LPS-challenged leeches at $30 \mathrm{~min}$ (Fig. 7a-c). Strikingly, electron microscope analysis clearly showed the presence of RNASET2-positive gold particles specifically localized in the granules of these cells (Fig. 7b). No gold particles were detected in control experiments in which the primary antibody was omitted (Fig. 7c) or substituted with preimmune serum (Fig. 7d). Besides confirming the expression of RNASET2 in granulocytes, these data also demonstrated that this enzyme was stored in their granules.
Evaluation of the Antibacterial Effect of RNASET2

The RNASET2 localization pattern in the electrondense granules of granulocytes prompted us to investigate whether this enzyme could directly or indirectly affect bacterial viability. To better evaluate this hypothesis, an in vitro eukaryotic-prokaryotic co-culture was set up.

The human monocytic leukemia-derived cell line (THP-1) was committed to differentiate into macrophage-like cells following treatment with phorbol esters, thus mimicking native monocyte-derived macrophages. We chose this experimental system because differentiated THP-1 cells represent a well-established model of in vitro macrophage differentiation when compared to other human myeloid cell lines [33]. In our co-culture assay, THP1 cells, which normally express and secrete high endogenous RNASET2 levels [Scaldaferri et al., submitted], were compared to their RNASET2-silenced counterpart (Fig. 8a-d) in the presence of the GFP-expressing PAO1 $P$. aeruginosa strain described in the Materials and Methods section.

Upon a 2 -h co-culture at $37^{\circ} \mathrm{C}$, bacteria cell integrity was checked by evaluating the GFP expression by fluorescence microscopy. Strikingly, the rod-like morphology of $P$. aeruginosa $\mathrm{PAO} 1$ cells co-cultured with parental RNASET2-expressing THP-1 cells could be hardly perceived and the GFP fluorescence signal appeared largely scattered, suggesting a bacterial stressful condition (Fig. 8a, c). By contrast, $P$. aeruginosa $\mathrm{PAO} 1$ cells co-cultured with RNASET2-silenced THP-1 cells maintained their cellular typical rod morphology (Fig. 8b, d). Bacterial viability has also been checked in both co-cultures with parental and RNASET2-silenced THP-1 cells, but no significant difference was observed after $2 \mathrm{~h}$ from the inoculum $\left(\sim 10^{7}\right.$ $\mathrm{CFU} / \mathrm{ml}$ ). Based on these results, GFP-expressing P. aeruginosa $\mathrm{PAO} 1$ cells were directly injected into the leech body wall (Fig. 8e-j) to evaluate the in vivo effects of leech RNASET2 on bacterial viability. The microorganisms were injected with and without a neutralizing anti-RNASET2 antibody, which does not induce an inflammatory response but functionally inhibits the endogenous leech RNASET2 protein function [2]. Leeches were sacrificed 30 min after infection, the time point at which a high expression of RNASET2 was correlated with a high number of granulocytes, and tissue sections were examined by optical and fluorescence microscopy. Strikingly, in vivo antibody-mediated blocking of the RNASET2 protein was associated with the observation of apparently undamaged bacteria, forming clusters in the connective tissue of the infected animals (Fig. 8e). These bacteria showed the typical rod shape easily recognizable by GFP (Fig. 8f) and 

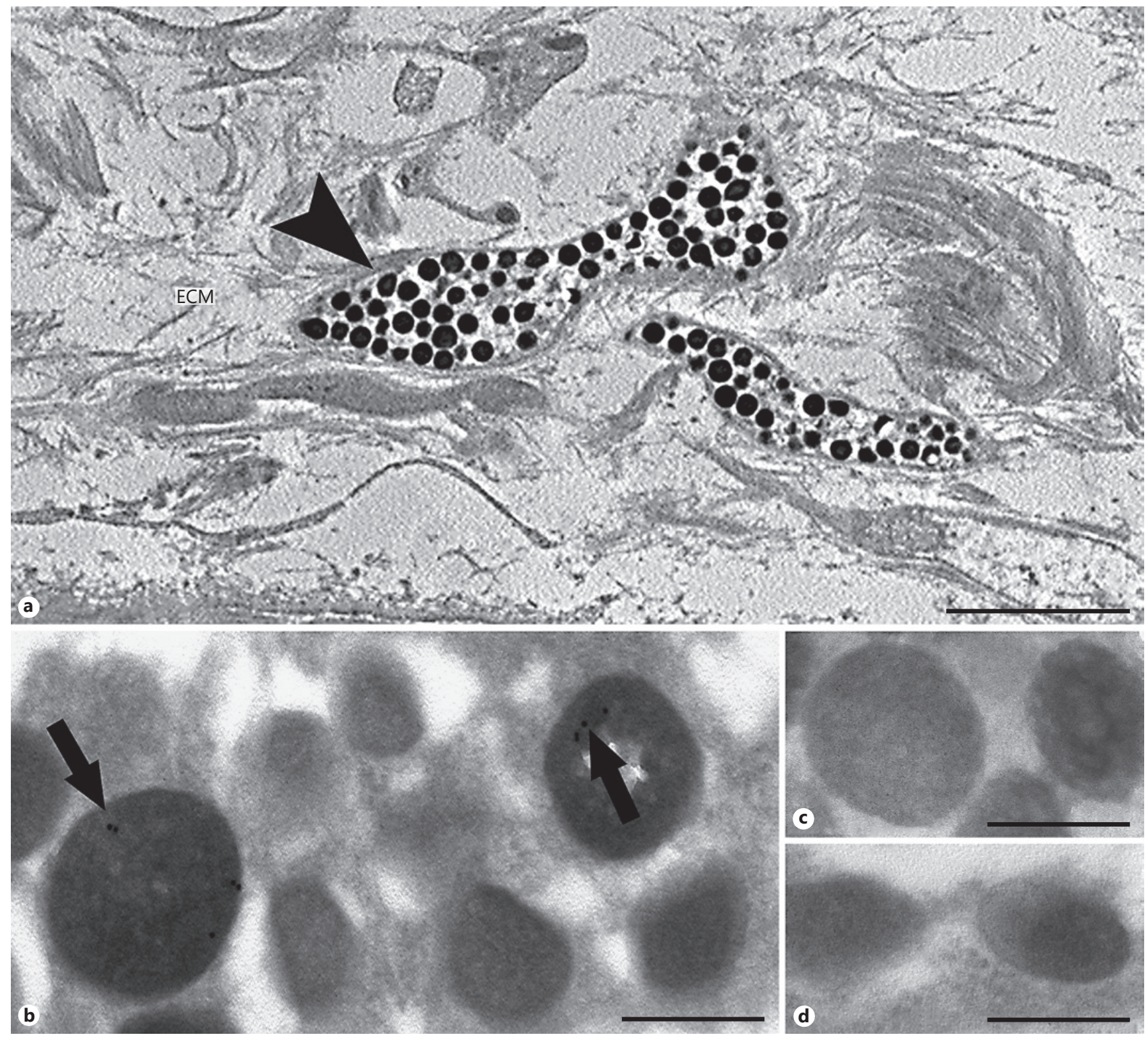

Fig. 7. Immunogold staining of RNASET2. Type I granulocytes (arrowhead in a) present in the extracellular matrix (ECM). b Detailed TEM showing the localization of gold particles in the granules (arrows). c, d Negative controls. Bar in $\mathbf{a}: 2.5 \mu \mathrm{m} ; \mathrm{bars}$ in $\mathbf{b}, \mathbf{c}, \mathbf{d}$ : $300 \mathrm{~nm}$.

Fig. 8. In vitro and in vivo analysis. $P$. aeruginosa $\mathrm{PAO} 1$ cells expressing GFP and co-cultured with RNASET2 silenced THP-1 cells (b, d, and inset) maintained their typical rod morphology, and GFP signal was localized inside the bacteria. On the other hand, in the presence of THP-1 expressing RNASET2 cells (a, c, and inset), GFP signal is widespread, indicating the PAO1 are in a stressful condition. Cryosection of leech body wall injected with GFP/PAO1 cells and an antibody anti-RNASET2 $(\mathbf{e}-\mathbf{g})$ or injected with GFP/PAO1 alone (h-j). e Violet and fuchsin staining shows the presence of bacteria agglomerates. GFP (f) and DAPI (g) signals highlight the characteristic rod shape of these bacteria. In absence of the functional blocking antibody anti-RNASET2, no bacteria are visible (h), and GFP (i) and DAPI (j) show a diffuse staining. The squares in $\mathbf{e}, \mathbf{h}$ indicate the magnified areas of $\mathbf{f}, \mathbf{g}, \mathbf{i}, \mathbf{j} . \mathbf{a}$, b. The merge of fluorescent channel with transmission image shows the position of bacteria with respect to eukaryotic cells. Bars in $\mathbf{a}-\mathbf{d}$ : $15 \mu \mathrm{m}$; bars in $\mathbf{e - j :} 4 \mu \mathrm{m}$.

(For figure see next page.)
AIF-1 and RNASET2 in Leech Innate Immune Response
J Innate Immun 2019;11:150-167

DOI: $10.1159 / 000493804$ 


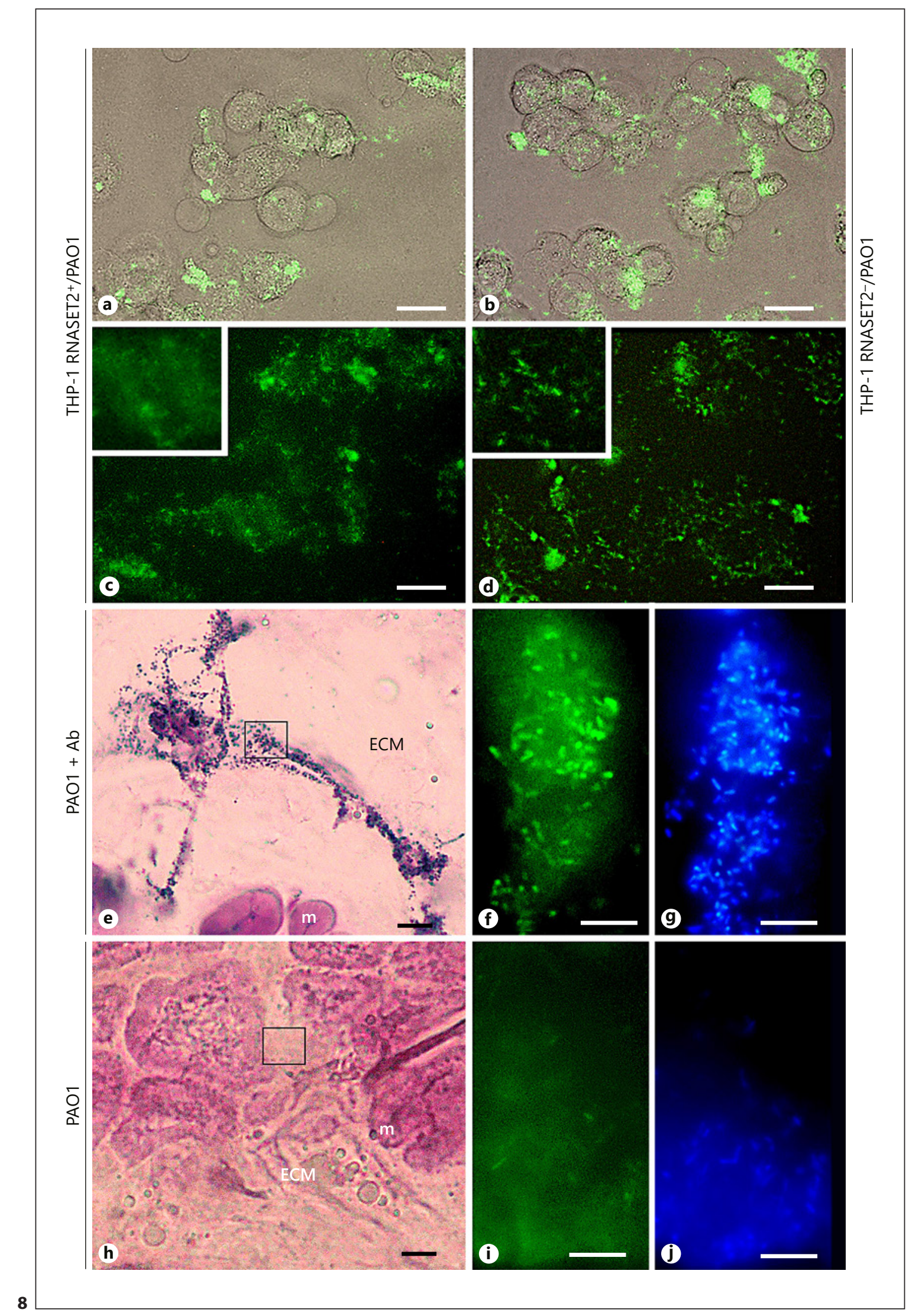


DAPI (Fig. 8g) signals, respectively. By contrast, in leech infected in the absence of neutralizing anti-RNASET2 antibody, no bacterial clusters were observed in the tissues (Fig. 8h) and a diffused GFP signal was detectable. Only a few intact bacteria were recognizable (Fig. 8i, j). These results support a possible RNASET2-mediated bacterial cell wall damage or a failure in expression machinery given that the GFP signal was not associated with bacteria cells.

Collectively, these data support our hypothesis that the RNASET2 protein might play an antimicrobial role.

\section{Discussion}

Several experimental reports have demonstrated a remarkable resemblance and evolutionary conservation of both the cell types and the underlying pathways by which Hirudinea and vertebrates trigger the inflammatory and immune response processes $[18,22]$. Hirudinea are continuously exposed to attack and invasion from potential pathogens such as microorganisms or parasites [41]. In order to deal with this constant threat, they are endowed with several effective strategies to recognize and destroy "not-self" molecules or microorganisms. Indeed, bacterial infections, wounds or allografts activate a complex defense response in leeches, including proliferation and migration towards the stimulated area of immunocompetent cells involved in phagocytosis, encapsulation of not-self agents, angiogenesis, fibroplasia, and reshaping of scar tissues [23-25, 42]. As mentioned above, these processes involve cellular mechanisms and key effector molecules that proved to be very similar to those deployed by vertebrates. Due to these remarkable similarities to vertebrates in inflammatory response and tissue repairing, medicinal leeches belonging to the Hirudo genus are thus increasingly exploited as an emerging, cost-effective, and valuable experimental model to investigate the mechanisms that underlie these biological processes [18, 22].

Within this frame, recent studies from our laboratories, focused on functional analyses of the immunomodulatory AIF-1 and RNASET2 proteins, allowed us to investigate the biological role played by these factors in the activation of the innate immune system in this animal model.

The allograft factor 1 (AIF-1) protein, a novel cytokine-like molecule involved in immunocyte recruitment into injured/grafted or infected tissues both in vertebrates $[6,7,43]$ and invertebrates $[8-10,44]$, has recently been characterized in leech by our research group. Indeed, a gene showing high similarity with vertebrates' AIF-1, named HmIba1/alias HmAIF-1, has been recently characterized in the central nervous system of the medicinal leech [11]. Of note, the expression of AIF-1 in leech has been reported to increase significantly after transplantation, wound healing, or bacterial infections, suggesting its involvement in the inflammatory response and in immune system regulation. Strikingly, immunohistochemical assays with an anti-HmAIF-1 polyclonal antibody revealed the presence of this protein in leech macrophagelike cells. Moreover, recombinant AIF-1 was shown to induce a massive migration of $\mathrm{CD} 45^{+} / \mathrm{CD}^{2} 8^{+}$macrophages towards infected of injured tissues [4].

In our previous work, a chemotactic role of leech cells belonging to the monocyte-macrophage lineage cells has been observed for RNASET2 as well. Indeed, injection of human recombinant RNASET2 in leeches induced a massive migration of macrophage-like cells towards the stimulated area, and endogenous RNASET2 was found to be expressed in leech's macrophages as well.

Although these previous data strongly implicate both AIF-1 and RNASET2 as evolutionary conserved mediators of the innate immune response, the specific mechanisms by which they regulate innate immune cells functions and that define their specific roles in inflammation and innate immune response activation remain largely unexplored. Our preliminary data strongly suggested that both molecules seem to play a similar role in the early stages of the inflammatory response but could also take part in later events that activate the immune response stimulating macrophage migration. However, neither the precise timing of action of both factors during the inflammatory response nor their putative functional interactions have been investigated so far.

Here, we provide further experimental evidence supporting a critical role of both factors in orchestrating a highly coordinated response against pathogen infection in medicinal leeches. To shed more light on these issues, we first analyzed the in vivo expression levels of both AIF1 and RNASET2 in tissues from LPS-injected leeches by immunoblot analysis at different times after treatment. This allowed us not only to confirm that AIF-1 and RNASET2 are both activated in the early inflammatory events, but also to unveil a peculiar temporal expression profile for these two cytokines. Since medicinal leeches present a very fast inflammatory response [24, 45], we decided to investigate the temporal expression profiles of both proteins at $30 \mathrm{~min}$ and 1, 3, 6, and $24 \mathrm{~h}$ following LPS injection. Quantitative analyses of the data clearly showed that, whereas AIF-1 and RNASET2 were constitutively 
Fig. 9. Representation to explain the different but complementary roles of RNASET2 and AIF-1 in early inflammatory response. 30 min after LPS stimulation, activated granulocytes secrete RNASET2, whose first effect is to carry out a direct antibacterial activity. In parallel, LPS-activated macrophages release AIF-1 in order to recruit other macrophages. These cells, releasing RNASET2, maintain the inflammatory state by recruiting other macrophages involved in cleaning the infected area from bacterial debris.

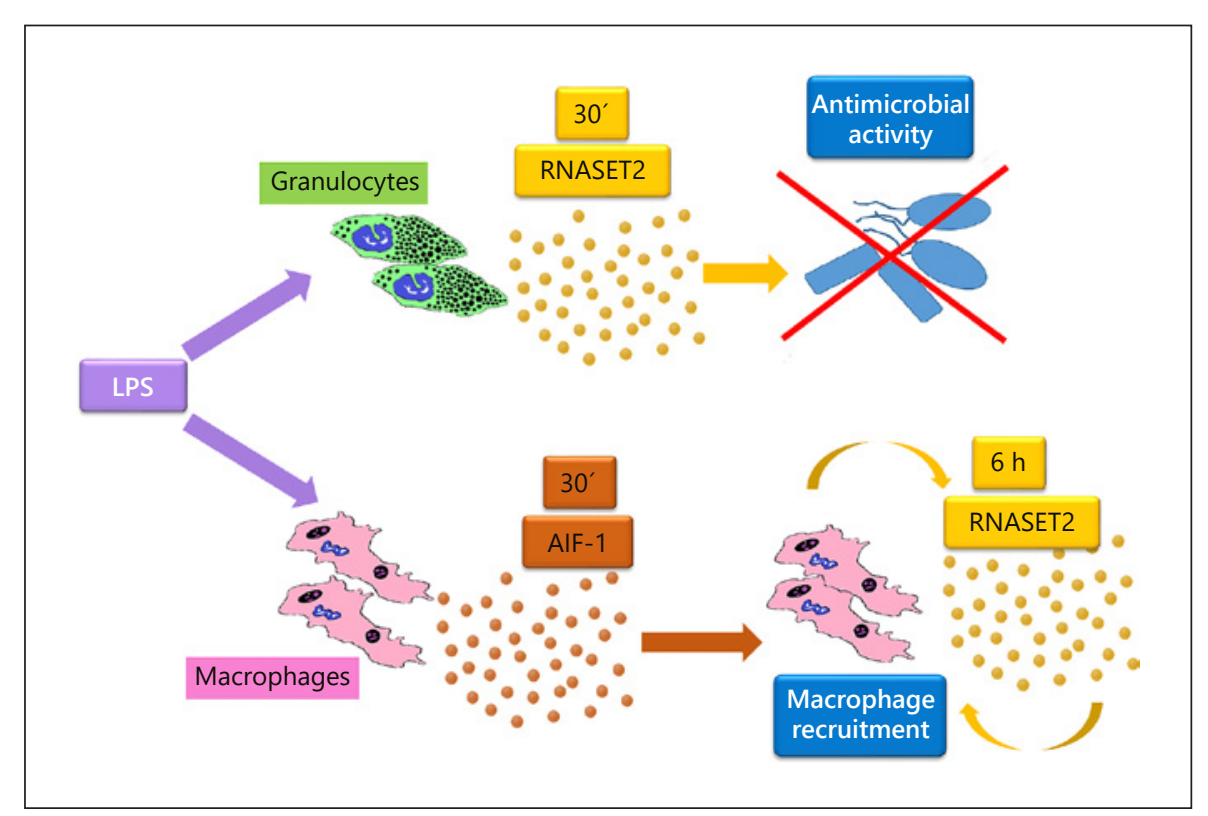

expressed at low basal level in healthy animals, LPS injection produced a marked change in their expression profile over time. In particular, AIF-1 expression significantly increased in the earliest phases of inflammation, followed by a slow but steady decline up to $24 \mathrm{~h}$. By contrast, RNASET2 expression significantly peaked at $30 \mathrm{~min}$ and $6 \mathrm{~h}$ after treatment.

In medicinal leeches, LPS injection is known to induce a massive migration and activation of immunocompetent cells, which are mainly localized in the connective tissue and near the body wall epithelium $[2,3]$. Double immunofluorescence experiments of LPS-injected leeches showed a massive recruitment of both CD $11 \mathrm{~b}^{+} /$RNASET2 ${ }^{+}$granulocytes and AIF- $1^{+} / \mathrm{RNASET}^{+}$macrophages underneath the epithelium and near the muscular fibers, with a signal specificity for each antibody in keeping with the data obtained by the previous Western blot analysis. By contrast, control samples analyzed following PBS injection showed a tissue architecture similar to unlesioned animals, indicating that neither the mechanical stress induced by injection nor the vehicle solution alone could significantly affect AIF-1 or RNASET2 expression.

Taken together, the observed AIF-1 and RNASET2 expression pattern clearly suggests the involvement of both proteins in the early inflammatory processes of $H$. verbana.

Moreover, the expression of RNASET2 by granulocytes, which to our knowledge has not been reported before, prompted us to evaluate the possible involvement of leech granulocytes in RNASET2 production and secretion. Our optical, ultrastructural, and immunohistochemical analyses of LPS-injected leeches confirmed that

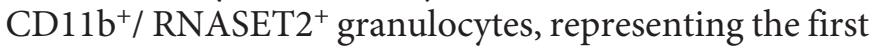
immunocompetent cells that are activated to trigger a defense response against microbial infections, are early recruited at the site of LPS injection. Moreover, RNASET2 turned out to be specifically confined in the granules of these cells, suggesting a possible antibacterial role of this protein. It is important to stress that several ribonucleases are known to be endowed with a strong antibacterial activity such as the RNASE A superfamily members RNase 3, 6, 7, and 8, whose antibacterial activity has been associated with disruption of the bacterial membrane $[46,47]$. In fact, these enzymes display a strong affinity for LPS of Gram-negative bacteria, take contact with the bacterial cellular membrane and subsequently destabilize the phospholipid double layer, finally triggering the agglutination and depolarization of the bacterial membrane $[48,49]$. Interestingly, several members of this RNase superfamily are often expressed in different types of immune cells [50]. For instance, EDN/RNase2 and $\mathrm{ECP} / \mathrm{RNase} 3$ have been detected in the secondary granules of eosinophils [51], whereas Rnase2 and RNase3 represent two actively secreted proteins that were found in the granules of these cells during an inflammatory response [52].

Following the detection of RNASET2 in the granules of $\mathrm{RNASET}^{+} / \mathrm{CD} 11 \mathrm{~b}^{+}$cells in LPS-challenged leeches, 
we set up in vitro and in vivo assays to evaluate the ability of Hirudo RNASET2 to affect $P$. aeruginosa PAO1 integrity. Strikingly, both assays strongly suggested that RNASET2 affects bacterial integrity. Although several antimicrobial peptides produced by medicinal leech have been described $[53,54]$, to our knowledge, this is the first report of the occurrence of an antibacterial activity of a ribonuclease protein in this animal model. The expression of RNASET2 seemed not to interfere with bacterial viability as outlined from viability assay in co-cultures. However, $P$. aeruginosa co-cultured with parental THP-1 cells released in the extracellular environment the GFP, suggesting a modification of membrane permeability. Although GFP release was apparently not able to influence cellular viability under the tested conditions, it could nevertheless represent the first part of a multistep in vivo antimicrobial response involving other immune system cells. The observed release of the GFP in both in vitro cocultures and in vivo could therefore be attributed to the direct effect of RNase T2 on the bacterial envelope. For instance, the cationic residues of RNASET 2 could bind to the anionic bacterial membrane to induce cell death [47]. However, an indirect antimicrobial effect of RNase T2 cannot be ruled out, and further investigations are needed to shed light on both hypothesized antimicrobial mechanisms.

Collectively, these results suggest that the innate immune response could be activated and modulated in medicinal leeches by the establishment of an AIF-1/RNASET2-mediated cross talk involving the recruitment and activation of granulocytes and macrophages, resulting in an effective defense against bacterial infections.

Thus, we can envisage an early inflammatory response in leeches, where both residents, LPS-activated AIF- $1^{+}$ macrophages, and CD11 $\mathrm{b}^{+}$LPS-recruited granulocytes actively produce and secrete RNASET2, whose effect is to send an alarm signal to nearby healthy tissue in order to recruit further innate immune cells and at the same time to carry out a direct antibacterial activity.

Moreover, the AIF-1 protein actively secreted by LPSactivated, resident macrophages contributes to immune cell recruitment as well $[3,4]$. At later stages $(6 \mathrm{~h}$ after treatment), a second boost of RNASET2 expression ensues to maintain the inflammatory state by means of recruitment of further macrophages (as shown by the resumed AIF-1 expression detected by Western blot analysis at $24 \mathrm{~h}$ ) in order to clean the infected area from bacterial debris.

\section{Conclusion and Future Perspectives}

Taken together, our data strongly suggest that, in addition to the well-established role of AIF-1 in triggering the innate immune response, the early phase of the inflammatory response in leeches is characterized by the contemporary release of RNASET2 and AIF-1 from immunocompetent cells, which might carry out different but complementary roles, namely bacterial killing and further innate immune cell recruitment. Moreover, at later stages of infection, RNASET2 might act mainly as a chemokine in order to attract new macrophages (which in turn produce RNASET2 by themselves) to further strengthen the inflammatory state (as schematically shown in Fig. 9).

Such dual role (antibacterial activity and innate immunity stimulation) played by RNASET2 represents a further demonstration of the pleiotropic role carried out by this class of ancient, evolutionary conserved ribonucleases. To confirm the evolutionary conserved function of RNASET2 in regulating the innate immune response, the role of the $H$. verbana RNASET2 gene in the response to bacterial infection will be investigated as well following the cloning of the corresponding gene's coding sequence. Moreover, we are currently implementing experimental protocols for endogenous RNASET2 gene knockdown in leeches, in order to develop functional assays aimed to further dissect the role of RNASET2 in inflammatory response.

\section{Acknowledgements}

Nicolò Baranzini is a PhD student of the "Biotechnology, Biosciences and Surgical Technology" course at University of Insubria; Debora Scaldaferri is a $\mathrm{PhD}$ student of "Experimental and Translational Medicine"; Acquati Francesco was supported by Federico Ghidoni memorial funds.

\section{Statement of Ethics}

The authors have no ethical conflicts to disclose.

\section{Disclosure Statement}

The authors have no conflicts of interest to declare. 


\section{Funding Sources}

This work was supported by the CARIPLO foundation (URL http://wwwfondazionecariplo.it), FRAMYEVO to M.d.E., grant code 2016-0835 and by FAR 2016-2017 (Fondi dell'Ateneo per la Ricerca, University of Insubria) to A.G., F.A., G.T., and R.T.

\section{Author Contributions}

A.G. and F.A. conceived and designed the experiments and wrote the main manuscript text; N.B. and M.V. performed the morphological, immunofluorescence, and immunogold analyses; L.M. performed Western blot assays; R.G. performed statistical analysis; D.S. cultured and differentiated THP-1 cells; F.B. transformed PAO1 for GFP expression; V.T.O. analyzed data of Figure 7; G.T. and M.d.E. provided expertise for TEM and imaging; J.V. provided anti-HmAIF-1 antibody and expertise for histocytochemistry and imaging; R.T. contributed to reagents. All authors critically reviewed the manuscript.

\section{References}

1 Frantz S, Vincent KA, Feron O, Kelly RA. Innate immunity and angiogenesis. Circ Res. 2005 Jan;96(1):15-26.

2 Baranzini N, Pedrini E, Girardello R, Tettamanti G, de Eguileor M, Taramelli R, et al. Human recombinant RNASET2-induced inflammatory response and connective tissue remodeling in the medicinal leech. Cell Tissue Res. 2017 May;368(2):337-51.

3 Schorn T, Drago F, Tettamanti G, Valvassori R, de Eguileor M, Vizioli J, et al. Homolog of allograft inflammatory factor-1 induces macrophage migration during innate immune response in leech. Cell Tissue Res. 2015 Mar; 359(3):853-64.

4 Schorn T, Drago F, de Eguileor M, Valvassori R, Vizioli J, Tettamanti G, et al. The Allograft Inflammatory Factor-1 (AIF-1) homologous in Hirudo medicinalis (medicinal leech) is involved in immune response during wound healing and graft rejection processes. Invertebrate Surviv J. 2015;12:129-141.

5 Utans U, Arceci RJ, Yamashita Y, Russell ME. Cloning and characterization of allograft inflammatory factor-1: a novel macrophage factor identified in rat cardiac allografts with chronic rejection. J Clin Invest. 1995 Jun; 95(6):2954-62.

6 Deininger MH, Seid K, Engel S, Meyermann R, Schluesener HJ: Allograft inflammatory factor-1 defines a distinct subset of infiltrating macrophages/microglial cells in rat and human gliomas. Acta Neuropathol 2000;100:673-80.

7 Watano K, Iwabuchi K, Fujii S, Ishimori N, Mitsuhashi S, Ato M, et al.: Allograft inflammatory factor- 1 augments production of interleukin- $6,-10$ and -12 by a mouse macrophage line. Immunology 2001;104:307-16.

8 Kruse M, Steffen R, Batel R, Müller IM, Müller WE: Differential expression of allograft inflammatory factor 1 and of glutathione peroxidase during auto- and allograft response in marine sponges. J Cell Sci 1999;112(Pt 23):4305-13.

9 Ovando F, Gimpel C, Cardenas C, Machado JR, Cunha M, da Silva C, et al. Cloning and Expression Analysis of Allograft Inflammatory Factor Type 1 in Coelomocytes of Antarctic Sea Urchin (Sterechinus neumayeri). J Shellfish Res. 2012;31(3):875-83.
10 Li J, Chen J, Zhang Y, Yu Z. Expression of allograft inflammatory factor-1 (AIF-1) in response to bacterial challenge and tissue injury in the pearl oyster, Pinctada martensii. Fish Shellfish Immunol. 2013 Jan;34(1):365-71.

11 Drago F, Sautière PE, Le Marrec-Croq F, Accorsi A, Van Camp C, Salzet M, et al. Microglia of medicinal leech (Hirudo medicinalis) express a specific activation marker homologous to vertebrate ionized calcium-binding adapter molecule 1 (Iba1/alias aif-1). Dev Neurobiol. 2014 Oct;74(10):987-1001.

12 Luhtala N, Parker R. T2 Family ribonucleases: ancient enzymes with diverse roles. Trends Biochem Sci. 2010 May;35(5):253-9.

13 Acquati F, Bertilaccio S, Grimaldi A, Monti L, Cinquetti R, Bonetti $\mathrm{P}$, et al. Microenvironmental control of malignancy exerted by RNASET2, a widely conserved extracellular RNase. Proc Natl Acad Sci USA. 2011 Jan; 108(3):1104-9.

14 Acquati F, Lualdi M, Bertilaccio S, Monti L, Turconi G, Fabbri M, et al. Loss of function of Ribonuclease T2, an ancient and phylogenetically conserved RNase, plays a crucial role in ovarian tumorigenesis. Proc Natl Acad Sci USA. 2013 May 14;110(20):8140-5.

15 Everts B, Hussaarts L, Driessen NN, Meevissen MH, Schramm G, van der Ham AJ, et al. Schistosome-derived omega-1 drives Th2 polarization by suppressing protein synthesis following internalization by the mannose receptor. J Exp Med. 2012 Sep;209(10):175367.

16 Xu Y, Chen W, Bian M, Wang X, Sun J, Sun $\mathrm{H}$, et al.: Molecular characterization and immune modulation properties of Clonorchis sinensis-derived RNASET2. Parasit Vectors. 2013 Dec 23;6:360.

17 Tettamanti G, Grimaldi A, Valvassori R, Rinaldi L, de Eguileor M: Vascular endothelial growth factor is involved in neoangiogenesis in Hirudo medicinalis (Annelida, Hirudinea). Cytokine 2003;22:168-79.

18 Grimaldi A, Tettamanti G, Perletti G, Valvassori R, de Eguileor M: Hematopoietic cell formation in leech wound healing. Curr Pharm Des 2006;12:3033-41.
19 Mann KH, Kerkut GA. Leeches (Hirudinea : their structure, physiology, ecology and embryology, with an appendix on the systematics of marine leeches. Amsterdam: Elsevier Science; 1962.

20 Sawyer RT. Leech biology and behaviour. Oxford: Clarendon Press; 1986.

21 de Eguileor M, Grimaldi A, Tettamanti G, Congiu T, Protasoni M, Reguzzoni M, et al. Ultrastructure and functional versatility of hirudinean botryoidal tissue. Tissue Cell. 2001 Aug;33(4):332-41.

22 Grimaldi A. Origin and fate of hematopoietic stem precursor cells in the leech Hirudo medicinalis. Invertebrate Surviv J. 2016;13:25768.

23 de Eguileor, Grimaldi A, Boselli A, Tettamanti G, Lurati S, Valvassori R, et al.: Possible roles of extracellular matrix and cytoskeleton in leech body wall muscles. J Microsc 1999; 196(1):6-18.

24 de Eguileor M, Grimaldi A, Tettamanti G, Valvassori R, Cooper EL, Lanzavecchia G: Different types of response to foreign antigens by leech leukocytes. Tissue Cell 2000;32: $40-8$.

25 de Eguileor M, Grimaldi A, Tettamanti G, Valvassori R, Cooper EL, Lanzavecchia G: Lipopolysaccharide-dependent induction of leech leukocytes that cross-react with vertebrate cellular differentiation markers. Tissue Cell. 2000 Oct;32(5):437-45.

26 Tettamanti G, Malagoli D, Benelli R, Albini A, Grimaldi A, Perletti G, et al.: Growth factors and chemokines: a comparative functional approach between invertebrates and vertebrates. Curr Med Chem 2006;13:273750.

27 Macagno ER, Gaasterland T, Edsall L, Bafna $\mathrm{V}$, Soares MB, Scheetz T, et al. Construction of a medicinal leech transcriptome database and its application to the identification of leech homologs of neural and innate immune genes. BMC Genomics. 2010 Jun; 11(1):407.

28 Grimaldi A, Tettamanti G, Rinaldi L, Perletti G, Valvassori R, De Eguileor M. Role of cathepsin B in leech wound healing. Invertebr Surviv J. 2004;38-46. 
29 Moore RD, Mumaw V, Schoenberg MD. Optical microscopy of ultrathin tissue sections. J Ultrastruct Res. 1960 Nov;4(2):113-6.

30 Campomenosi P, Cinquetti R, Tallarita E, Lindqvist C, Raimondi I, Grassi P, et al. Comparison of the baculovirus-insect cell and $\mathrm{Pi}$ chia pastoris heterologous systems for the expression of the human tumor suppressor protein RNASET2. Biotechnol Appl Biochem. 2011 Jan-Feb;58(1):39-49.

31 Schnell SA, Staines WA, Wessendorf MW. Reduction of Lipofuscin-like Autofluorescence in Fluorescently Labeled Tissue. J Histochem Cytochem 1999;47:719-30.

32 Causton BE: Improved bonding of composite restorative to dentine. A study in vitro of the use of a commercial halogenated phosphate ester. Br Dent J 1984;156:93-5.

33 Auwerx J: The human leukemia cell line, THP-1: a multifacetted model for the study of monocyte-macrophage differentiation. Experientia 1991 Jan 15;47(1):22-31.

34 Stover CK, Pham XQ, Erwin AL, Mizoguchi SD, Warrener P, Hickey MJ, et al. Complete genome sequence of Pseudomonas aeruginosa PAO1, an opportunistic pathogen. Nature. 2000 Aug;406(6799):959-64.

35 Huguet G, Molinas M. The pseudoblastema in the wound healing process of the leech $\mathrm{Hi}$ rudo medicinalis L. (Hirudinea): changes in cell junctions. J Exp Zool. 1994 May;269(1): 23-36.

36 Huguet G, Molinas M. Myofibroblast-like cells and wound contraction in leech wound healing. J Exp Zool. 1996;275(4):308-16.

37 Grimaldi A, Banfi S, Vizioli J, Tettamanti G, Noonan DM, de Eguileor M. Cytokine loaded biopolymers as a novel strategy to study stem cells during wound-healing processes. Macromol Biosci. 2011 Aug;11(8):1008-19.

38 Otero-González AJ, Magalhães BS, GarciaVillarino M, López-Abarrategui C, Sousa DA, Dias SC, et al. Antimicrobial peptides from marine invertebrates as a new frontier for microbial infection control. FASEB J. 2010 May; 24(5):1320-34.
39 Destoumieux D, Muñoz M, Cosseau C, Rodriguez J, Bulet P, Comps M, et al.: Penaeidins, antimicrobial peptides with chitin-binding activity, are produced and stored in shrimp granulocytes and released after microbial challenge. J Cell Sci 2000;113(Pt 3): 461-469.

40 Campomenosi P, Salis S, Lindqvist C, Mariani D, Nordström T, Acquati F, et al. Characterization of RNASET2, the first human member of the Rh/T2/S family of glycoproteins. Arch Biochem Biophys. 2006 May;449(1-2):17-26.

41 Silver AC, Rabinowitz NM, Küffer S, Graf J. Identification of Aeromonas veronii genes required for colonization of the medicinal leech, Hirudo verbana. J Bacteriol. 2007 Oct; 189(19):6763-72.

42 Tettamanti G, Grimaldi A, Congiu T, Perletti G, Raspanti M, Valvassori R, et al. Collagen reorganization in leech wound healing. Biol Cell. 2005 Jul;97(7):557-68.

43 Kuschel R, Deininger MH, Meyermann R, Bornemann A, Yablonka-Reuveni Z, Schluesener HJ: Allograft inflammatory factor- 1 is expressed by macrophages in injured skeletal muscle and abrogates proliferation and differentiation of satellite cells. J Neuropathol Exp Neurol 2000;59:323-32.

44 Zhang L, Zhao J, Li C, Su X, Chen A, Li T, et al. Cloning and characterization of allograft inflammatory factor-1 (AIF-1) from Manila clam Venerupis philippinarum. Fish Shellfish Immunol. 2011 Jan;30(1):148-53.

45 de Eguileor M, Grimaldi A, Tettamanti G, Ferrarese R, Congiu T, Protasoni M, et al.: Hirudo medicinalis: a new model for testing activators and inhibitors of angiogenesis. Angiogenesis 2001;4:299-312.

46 Nitto T, Dyer KD, Czapiga M, Rosenberg HF. Evolution and function of leukocyte RNase A ribonucleases of the avian species, Gallus gallus. J Biol Chem. 2006 Sep;281(35):25622-34.
47 Pizzo E, Varcamonti M, Di Maro A, Zanfardino A, Giancola C, D’Alessio G. Ribonucleases with angiogenic and bactericidal activities from the Atlantic salmon. FEBS J. 2008 Mar; 275(6):1283-95.

48 Torrent M, Badia M, Moussaoui M, Sanchez D, Victò Ria Nogué M, Boix E: Comparison of human RNase 3 and RNase 7 bactericidal action at the Gram-negative and Gram-positive bacterial cell wall. FEBS J. 2010 Apr; 277(7):1713-25.

49 Pulido D, Torrent M, Andreu D, Nogués MV, Boix E. Two human host defense ribonucleases against mycobacteria, the eosinophil cationic protein (RNase 3) and RNase 7. Antimicrob Agents Chemother. 2013 Aug;57(8): 3797-805.

50 Gupta SK, Haigh BJ, Griffin FJ, Wheeler TT. The mammalian secreted RNases: mechanisms of action in host defence. Innate Immun. 2013 Feb;19(1):86-97.

51 Shamri R, Xenakis JJ, Spencer LA. Eosinophils in innate immunity: an evolving story. Cell Tissue Res. 2011 Jan;343(1):57-83.

52 Koczera P, Martin L, Marx G, Schuerholz T. The ribonuclease a superfamily in humans: canonical RNases as the buttress of innate immunity. Int J Mol Sci. 2016 Aug;17(8):E1278.

53 Tasiemski A, Salzet M. Neuro-immune lessons from an annelid: the medicinal leech. Dev Comp Immunol. 2017 Jan;66:33-42.

54 Schikorski D, Cuvillier-Hot V, Leippe M, Boidin-Wichlacz C, Slomianny C, Macagno E, et al. Microbial challenge promotes the regenerative process of the injured central nervous system of the medicinal leech by inducing the synthesis of antimicrobial peptides in neurons and microglia. J Immunol. 2008 Jul; 181(2):1083-95.

55 Grimaldi A, Tettamanti G, de Eguileor M. Annelida: Hirudinea (leeches): heterogeneity in leech immune responses. In: Cooper E, editor. Advances in comparative immunology. Cham: Springer; 2018. Chapter 8. 